\title{
PLM Components Selection Based on a Maturity Assessment and AHP Methodology
}

\author{
Haiqing Zhang ${ }^{1}$, Yacine Ouzrout ${ }^{1}$, Abdelaziz Bouras ${ }^{1}$, Antonio Mazza ${ }^{2}$, \\ and Matteo Mario Savino ${ }^{2}$ \\ ${ }^{1}$ DISP Laboratory, University Lumière Lyon 2, France \\ 160 Bd de l'Université 69676 Bron Cedex \\ \{haizhang, yacine.ouzrout, abdelaziz.bouras\} @univ-lyon2.fr \\ ${ }^{2}$ University of Sannio - Dept. of Engineering, Italy \\ Piazza Roma, 21 - 82100 Benevento \\ \{matteo.savino, antonio.mazza\}@unisannio.it
}

\begin{abstract}
The benefits of Product Lifecycle Management (PLM) have been noted for improving business, creating collaboration, and reducing energy and time by making transcendent decisions through the process of product life

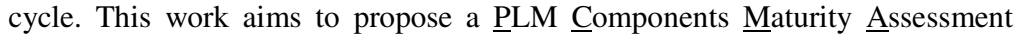
(PCMA) model to gain comprehensive maturity results and reduce the complexity in obtaining maturity scores. According to PLM functionalities, we divide PLM into fifteen components. PLM components can be cataloged into five main fields: 'TechnoWare', 'InforWare', 'FunctionWare', 'OrgaWare', and 'SustainWare' (TIFOS Framework). With PCMA model we analyzed PLM components and proposed mature content of each dimension, obtaining specific key performance indicators for each dimension. This work has been also useful to solve decision-making issues based on AHP methodology, such as: selecting the optimal PLM components in TIFOS Framework, obtaining the components ranking weight, getting components maturity score, and comparing it with the actual situation to give constructive business suggestions. These business suggestions include strengths and weakness of PLM components and conducting selection of PLM components. Experimental studies have been conducted to verify maturity scores for each component and to achieve component-ranking weights.
\end{abstract}

Keywords: PLM Maturity Model, AHP Methodology, Key Performance Indicators, TIFOS Framework.

\section{$1 \quad$ Introduction}

The concepts of PLM are very extensive (Stark et al., 2011). PLM manages and accesses product information to make companies run smooth and secure. PLM guarantees persistent integrity of product definitions and related information during the life of a product. The functionalities of PLM include maintaining business processes, such as: creating, managing, disseminating, and sharing product information (Stark et al., 2011). The foundation components are used to construct 
these PLM functionalities. The integration of several components is a PLM solution. Selecting right PLM components lead to a better PLM solution, which has substantial opportunity to meet company requirements. In contrast, misuse of PLM components will cause products to malfunction or fail.

The main purpose of this work is to help companies to select the right PLM components with their different goal oriented objectives. To achieve this aim, four basic research questions need to be addressed:

1. What are the full PLM functionalities that have to be considered in relation to PLM capabilities?

2. How many components constitute these PLM functionalities?

3. How can we identify the strengths and weaknesses of PLM components?

4. Which one is the most suitable PLM component for a company?

To answer the first research question, two important literature works are presented and a new framework is proposed in section 2.1. To answer the second question, the basic literature on PLM components is presented and fifteen PLM components are proposed in section 2.3. To answer the third question, a PLM maturity model has been proposed by analyzing characters and KPIs of PLM components in section 3. To answer the fourth question, AHP (Analytic Hierarchy Process) methodology is developed in section 4. Section 5 gives the case study and section 6 concludes our work.

\section{TIFOS Framework and PLM Components}

\subsection{TIFOS Framework}

Firstly, from Sharif's perspective (Sharif, 1997), technology can be classified into four categories: TechnoWare, InforWare, HumanWare, and OrgaWare.

- TechnoWare: contains components, equipment (manual and powered), vehicles, machinery, IT and other facilities;

- InforWare: contains documents or knowledge records that reflect facts and formulas (design parameters, standards), principles of physical and social phenomena; computer software; technical information; theories and state-of-theart knowledge for innovation;

- HumanWare: describes the skills to comprehend and use the job related components; the ability to utilize technology components; have the motivation to improve the work performance;

- OrgaWare: consists in organizational techniques, work assignments, education, and experience-based work facilitation; has the means for using and controlling factors of production, systems analysis, organization of products, processes, and components.

Secondly, from Vengugopalan et al.'s perspective (Vengugopalan et al, 2008), the functionalities of PLM are classified into four major categories based on TIFO Framework (TechnoWare, InfoWare, FunctionWare, and OrgaWare). They mixed the 
initial HumanWare with the OrgaWare components and added a new FunctionWare category:

- $\quad$ FunctionWare: depth and breadth of functionalities.

Every product life cycle is characterized by three phases: beginning of life (BOL), middle of life (MOL), and end of life (EOL). Most previous works focus on the BOL (design and manufacturing) phase (Kiritsis et al, 2010). However, in order to get tangible products, achieve top range performance, and obtain optimum product lifecycle, businesses must extend to EOL phase, which is PLM sustainability (Kiritsis et al, 2010). Next, we give the reasons why sustainability should be added into PLM functionalities.

PLM sustainability is the potential for a long-term maintenance of product lifecycle (Trotta et al, 2010). To meet the requirements of product performance, present designer decisions heavily impact upon product design (BOL phase) as well as on environmental aspects (EOL phase). To minimize efforts, time, and costs for improving product quality, businesses need sustainable, stable process management, and product development. Analysis, synthesis, evaluation and improvement of product lifecycle design, DFE (Design for Environment), TRIZ (Theory of Inventive Problem Resolution), and LCA (Life Cycle Assessment) need to be integrated and collaborated with PLM.

Based on what was mentioned above, we extend the TIFO framework into TIFOS and add a new category called SustainWare. The content of SustainWare is:

- SustainWare: reducing waste and pollution; designing eco-friendly products; using new materials and supply chain; minimizing damage to environment and human; consuming low energy.

\subsection{Successful Sustainability Indicators to Obtain Sustainable PLM}

In current literature studies, sustainability indicators and concepts have been studied and defined based on five dimensions: economy, ecology, society, technology, and performance management. Number these five dimensions in sequence: 1, 2, 3, etc. First, we will discuss presently acceptable and better recognized indicators for sustainable PLM.

Efforts are made by multiple organizations. An effort by the United Nations Environment Program (UNEP) and the United States nongovernmental organization called Global Reporting Initiative (GRI) (GRI, 2011) has defined more than 100 indicators and focused the first three dimensions. Other efforts by the National Institute of Standards and Technology (NIST) is the Sustainable Manufacturing Indicator Repository (SMIR) (SMIR, 2012), which defined extensively available indicator sets by using the five dimensions.

Efforts have been made by researchers to study system sustainable indicators. Laurent et al. studied the ability of carbon footprint emissions as an indicator, eager to find out the correlation between carbon footprints and other environmental impacts (Laurent et al., 2010). Fang et al. developed sustainable manufacturing metrics to measure sustainability performance in entire product lifecycle based on the first three dimensions (Fang et al., 2010). Trotta et al. analyzed important tools to formalize information and knowledge for sustainable new product development in companies (Trotta et al., 2010). We investigated the literature studies to give a list of 19 successful sustainability indicators based on four dimensions (Table 1). 
Table 1. Successful sustainability indicators to obtain sustainable PLM from literature

\begin{tabular}{|c|c|c|c|}
\hline Dimensions & Sustainability indicators & Dimensions & Sustainability indicators \\
\hline \multirow[t]{5}{*}{ Economy } & Investment & \multirow[t]{6}{*}{ Society } & Labor Practices \\
\hline & Economic performance & & Human Rights \\
\hline & $\begin{array}{l}\text { Product Presence in the } \\
\text { market }\end{array}$ & & Social influence \\
\hline & Green Process Design & & Product Responsibility \\
\hline & Green Manufacturing & & Eco-design Responsibility \\
\hline \multirow[t]{5}{*}{ Ecology } & Energy emissions & & $\begin{array}{l}\text { Innovative new materials } \\
\text { care }\end{array}$ \\
\hline & Carbon Foot Print & \multirow[t]{4}{*}{ Technology } & Life Cycle Assessment \\
\hline & Waste Reduction & & $\begin{array}{l}\text { Design for Environment } \\
\text { tools }\end{array}$ \\
\hline & Water Usage & & Zero Emissions \&Waste \\
\hline & Compliance & & \\
\hline
\end{tabular}

\subsection{PLM Components}

Now we will define how many important components PLM has and what they are on the basis of the TIFOS framework. Stark et al. presented that PLM is a holistic approach, which contains nine PLM components: products, data, applications, processes, people, work methods, and equipment (Stark et al., 2011). Abramovici et al. defined five PLM levels; every PLM levels is described by several concrete PLM components that can have interdependencies with other components (Abramovici et al., 2012). After comprehensively analyzing PLM functionalities and reviewing the works, which have been done by the other researchers, fifteen different types of PLM components have been collected and showed in Table 2 .

Table 2. TIFOS Frameworks and corresponding components

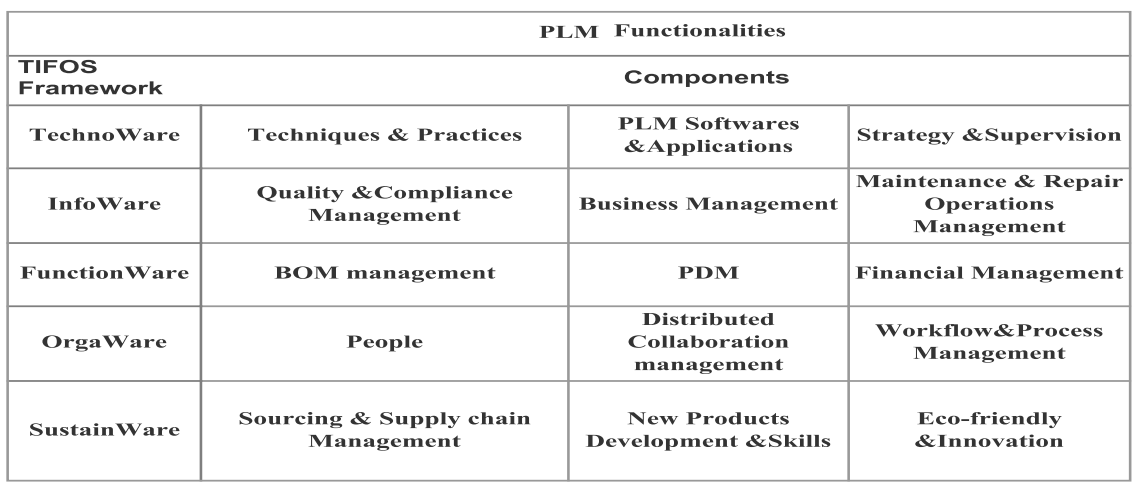

A PLM maturity model needs to be proposed to measure the current maturity situation of each PLM component, which can help the company identify strengths and weaknesses of PLM components. Evaluation of the integration and maturity of 
different components is essential and advantageous. For instance, PDM (Product Data Management) maturity models (Stark, 2005) define the activities that a company needs to carry out at each stage and also defines a generic five-step process per stage; related to the as-is situation and to-be situation of the studied company. CPI (Collaborative Product Innovation) maturity model (Sharma, 2005) proposes three unique stages of CPI based on collaborative maturity. Batenburg (Batenburg, 2006) developed a PLM framework to assess and guide PLM implementations. Sääksvuori Model (Sääksvuori \& Immonen, 2008) determines the maturity of a large international corporation for a corporate-wide PLM development program and develops business and PLM related issues. Other maturity models include Savino model (Savino et al, 2012) and BPMM (looy et al, 2012). But it should be mentioned that none of these maturity models have solved the following questions:

1 Complete degree of PLM areas: how many dimensions that need to be studied to cover all of the necessary PLM themes to get comprehensive results;

2 Relative importance of dimensions to the overall PLM maturity level: needed to strategize for allocation of structural weights of different dimensions based on different business needs.

Next step, we will propose a maturity model which can solve these two questions.

\section{$3 \quad$ Maturity Model to Assess Maturity Level of PLM Components}

This paper has considered viewpoints of different maturity models, analyzed success factors and key performance indicators of each component, then proposed a PLM Maturity Model called PLM Components Maturity Assessment (PCMA). This maturity model follows the principle structure of capability maturity model by using the same maturity levels and structured questionnaires. CMMI defined process maturity is developed incrementally from one level to the next level and it does not allow for skipping levels. This limitation of CMMI will result in misleading interpretations. This work gives detailed information of fifteen components in each maturity level in which the maturity is assessed separately, and the items of maturity descriptions are outlined in Table 3.

Table 3. PCMA Maturity Level and Corresponding Content

\begin{tabular}{|l|l|llll|}
\hline $\begin{array}{l}\text { Maturity } \\
\text { Levels }\end{array}$ & $\begin{array}{l}\text { CMMI(Short } \\
\text { Description) }\end{array}$ & Our Work (Items for Maturity Levels) & \\
\hline & $\begin{array}{l}\text { The activity is done with expediency } \\
\text { 1 ad-hoc }\end{array}$ & $\begin{array}{l}\text { Process } \\
\text { unpredictable }\end{array}$ & $\begin{array}{l}\text { Nobody is responsible for PLM } \\
\text { Documentation is at the lowest point to satisfy } \\
\text { operational needs } \\
\text { PLM software system and processes } \\
\text { deficiencies }\end{array}$ & have \\
\hline
\end{tabular}


Table 3. (continued)

\begin{tabular}{|c|c|c|}
\hline 2 Managed & $\begin{array}{l}\text { Process } \\
\text { reactive }\end{array}$ & $\begin{array}{l}\text { - The activity is defined and managed, but it is } \\
\text { repetitious } \\
\text { - } \quad \text { Documentation and record is carefully studied } \\
\text { Mutual actions are finished in processes and } \\
\text { departments } \\
\text { - No effort has been made to consider about recycling }\end{array}$ \\
\hline 3 Defined & $\begin{array}{l}\text { Process } \\
\text { proactive }\end{array}$ & $\begin{array}{ll}\text { - } & \text { The activity is formalized and supported by standards } \\
\text { - } & \text { Documentation and record is studied and shared } \\
\text { - } & \text { Personal actions are carried out efficiently } \\
\text { - } & \text { PLM systems are easily implemented } \\
\text { - } & \text { Environmental awareness occurs }\end{array}$ \\
\hline $\begin{array}{l}4 \\
\text { Quantitatively } \\
\text { managed }\end{array}$ & $\begin{array}{l}\text { Process } \\
\text { measured \& } \\
\text { controlled }\end{array}$ & $\begin{array}{l}\text { - } \text { Activities run smoothly } \\
\text { PLM systems cooperate with other enterprise } \\
\text { - } \quad \text { The products run efficiently and are effective } \\
\text { - } \quad \text { Progressively eliminates errors and failures }\end{array}$ \\
\hline 5 optimized & $\begin{array}{l}\text { Continuous } \\
\text { process } \\
\text { improvement }\end{array}$ & $\begin{array}{l}\text { - The activity runs optimally } \\
\text { - PLM system helps company make improved } \\
\text { decisions } \\
\text { - Best practices and innovative ideas are considered }\end{array}$ \\
\hline
\end{tabular}

PCMA serves the goal of measuring, monitoring, and comparing PLM components in relative and absolute terms. It provides a holistic assessment for fifteen PLM components based on a comprehensive set of key performance indicators (KPI) in each maturity level. Table 4 summarizes on what needs to be accomplished for "People" dimension in each maturity level. In order to simplify assessment work, avoid missing information, and improve the measurement of progress, we propose KPIs for each dimension, develop questionnaires, and obtain maturity scores based on KPI. For example, we outline the overall KPI of "people" dimension; the maturity score range of "Level 1" is $0-1$, the maturity score is 0.5 for each KPI, the maturity score of "People" dimension is the average of all KPIs' score. Similarly, we can obtain the maturity score of every dimension.

\section{Selection the Optimal PLM Components Based on Company Requirements}

The AHP method is a multi-criteria, multi-item decision-making technique (Carlos et al., 2008). It involves in structuring multiple criteria into a hierarchy and assessing the relative importance of these criteria, while comparing alternatives for each criterion, and obtaining an overall ranking of the alternatives. This process has been conceptualized as a hierarchical composition of 'Goals', 'Criteria', and 'Alternatives'. Selecting the optimal PLM components based on business profits can be approached by the AHP method. The objective is to choose PLM components in the TIFOS framework represented by O1 (TechnoWare), O2 (InforWare), O3 (FunctionWare), 
O4 (OrgaWare) and O5 (SustainWare). The features of O1-O5 can be selected as "Criteria" in the second hierarchy. Each criterion is individually connected to the competing alternatives, which come from PLM components (T1-T15), (limited in the examples given in this paper to T9).

We first determine the priorities of each PLM component. Priorities for each criterion are calculated from their importance in reaching the goal. The priorities are then combined throughout the hierarchy to get an overall priority for each component. The component with the highest priority will be the best alternative, and the ratios of PLM components' priorities indicate their relative importance to the goal. The decision process is described in depth in Figure 1.

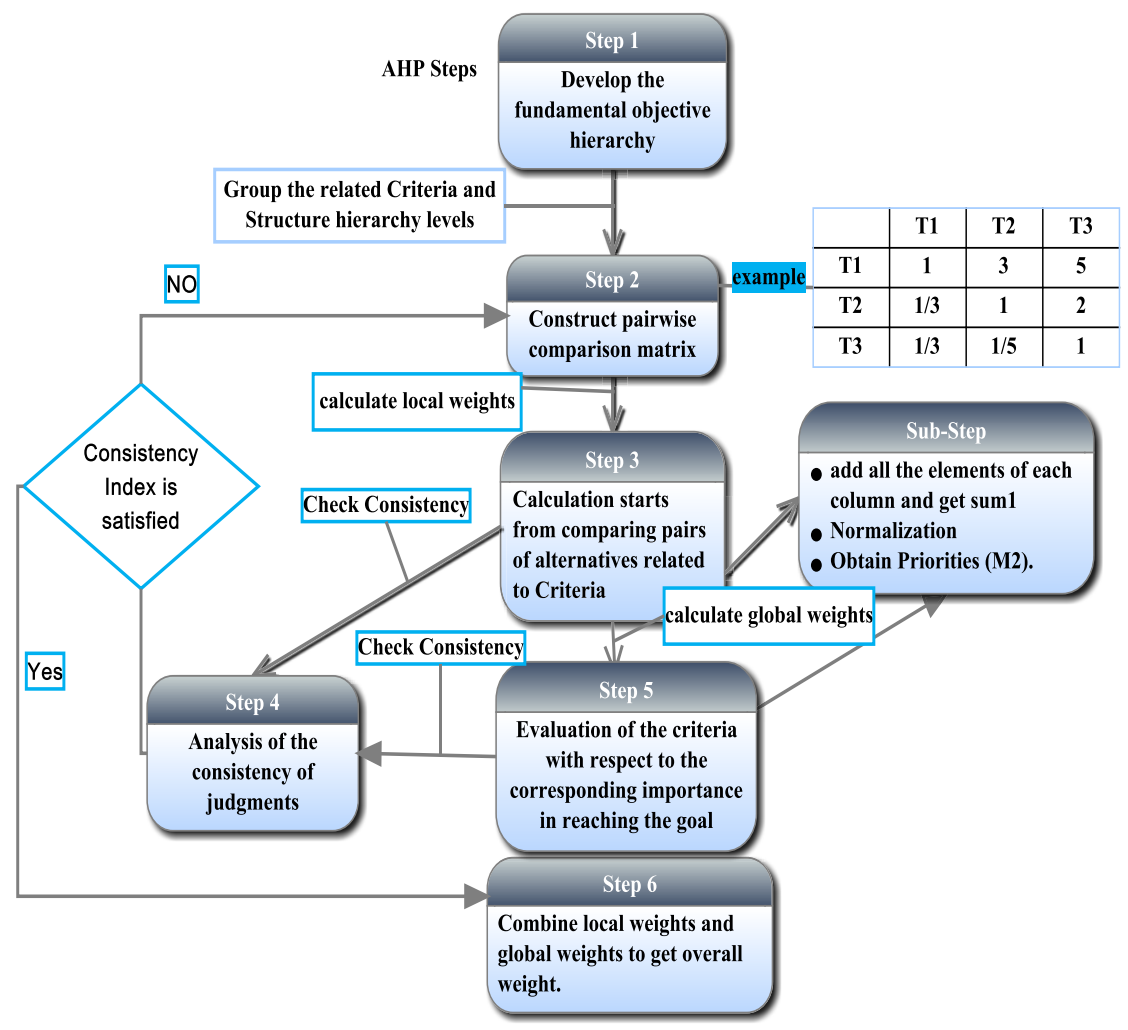

Fig. 1. AHP calculation steps

In figure 1 , the equation to get overall weights (step 6) is:

$$
W_{j}=\sum_{i=1}^{n} w_{i} a_{i_{j}} \forall i \in(1,2, \ldots, n) \forall j \in(1,2, \ldots, m)
$$

Where, $\mathrm{W}_{\mathrm{j}}$ is the priority value of the alternative $\mathrm{j} ; \mathrm{W}_{\mathrm{i}}$ is the priority value of criteria $\mathrm{i} ; \mathrm{a}_{\mathrm{ij}}$ is the priority value of the alternative $\mathrm{j}$ related to criteria $\mathrm{i} . \mathrm{m}$ is the number of alternatives and $\mathrm{n}$ is the number of criteria. 


\section{$5 \quad$ Case Studies}

This section focuses on case studies. Two parts are studied in this section: evaluating PCMA for a particular unit to get a maturity score; and choosing the right PLM components from the defined business targets. Experimental data and important information have been collected by interviewing the managers of an Italian prefabrication company.

We calculate final maturity score per PCMA dimension by calculating the weighted sum of the KPIs in each dimension; and determine the overall PCMA maturity as the mean score of the fifteen dimensions. The result can be seen in the radar chart (figure 2) showing the level of achievement for each dimension (limited in the examples given in this paper to T6).

Our work developed AHP methodology and derived priorities of PLM components. Describe the components' weight by using the descending order in figure 3. We define business profit goals as 'Reduce time-to-market' and achieve features of it as criteria, while adopting fifteen PLM components as alternatives. PLM components' weight is shown in figure 4.

Figure 2 shows the average score over all assessments. The yellow line represents the as-is situation. Among six dimensions, PLM applications are scoring highest with 3.8, and financial management scores lowest with 1.9 . The overall maturity score is 2.76 . From figure 3, we can obtain which PLM component is relatively important in the TIFOS framework. Figuring out strengths and weaknesses of PLM components in figure 2 and analyzing components relative importance in figure 3; we can work out future maturity scores of PCMA (blue dash line in figure 2). According to figure 2 and figure 3, the PLM application component helps to gain more profits than the other components, therefore, recommending the company to strengthen management of this component. In figure 4, when a business profit goal is 'Reduce time-to market', the optimal PLM components that should be selected are: PLM Applications, and Business Management.

Business actions are blind to many PLM components. However, this model, it is convenient to figure out which component is more important and improve. In conclusion, it is beneficial for the companies to make well educated choices when choosing the right PLM components by using less effort and time.

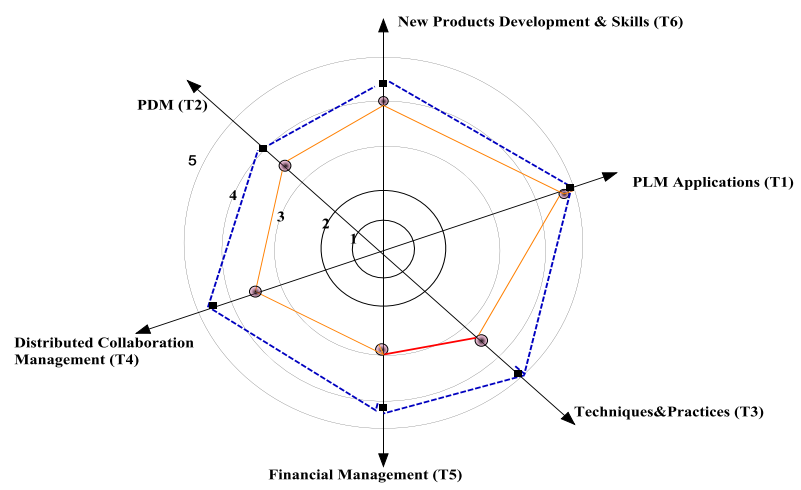

Fig. 2. PCMA Maturity Score 


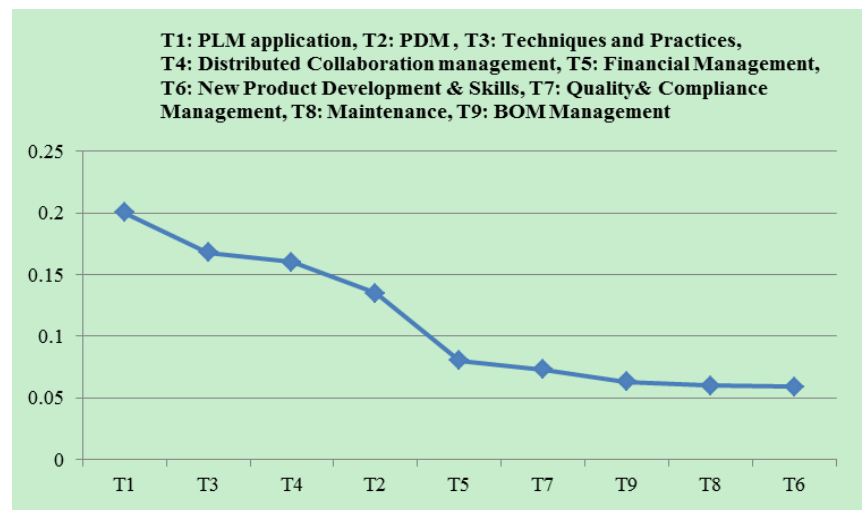

Fig. 3. PLM components' ranking and corresponding weight value

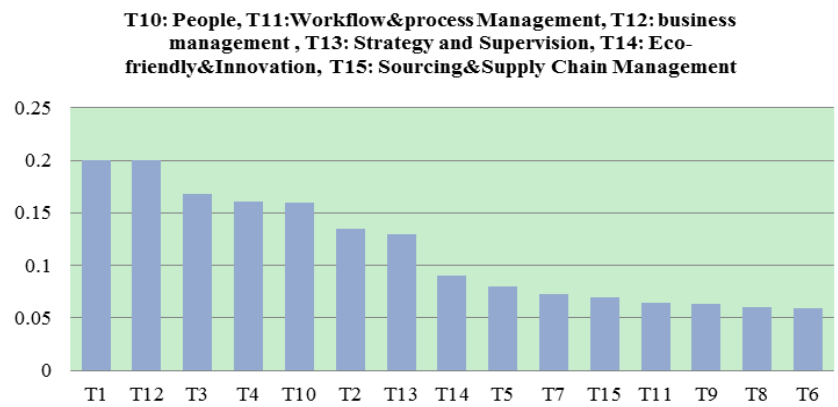

Fig. 4. PLM components' ranking based on 'Reduce time-to-market' goal

\section{Conclusion and Future Work}

This research work proposes an extension of the TIFO framework by adding Sustainability. This new framework, TIFOS, can cover entire functionalities of PLM and contains all PLM components. We introduced PCMA maturity model to evaluate the performance of each PLM component based on TIFOS. PCMA maturity score is given by assessing the characters and KPIs, which can entirely cover all PLM areas and reflects the strengths and weaknesses of PLM components. Then we selected optimal PLM components in TIFOS by developing AHP methodology, which is a weighting process in competing alternatives via pair-wise comparison matrices. Finally, we have done an experimental study to achieve PCMA as-is and to-be maturity scores, to select the optimal PLM components based on weight priorities.

The future work will use more realistic data to examine the effectiveness of the PCMA Model, concentrate on the consistency ratio of AHP, and test criteria and KPIs validations. Then we will develop Fuzzy AHP method to handle the uncertainty of the collected data. 


\section{References}

1. Abramovici, M., Göbel, J.C.: Decision Support Framework for PLM Harmonization Projects within Industrial Companies. In: Rivest, L., Bouras, A., Louhichi, B. (eds.) PLM 2012. IFIP AICT, vol. 388, pp. 535-546. Springer, Heidelberg (2012)

2. Batenburg, R., Helms, R.W., Versendaal, J.: PLM roadmap: Stepwise PLM implementation based on the concepts of maturity and alignment. Int. J. Product Lifecycle Management 1(4), 333-351 (2006)

3. Carlos, A., Vansnick, J.-C.: A Critical Analysis of the Eigenvalue Method Used to Derive Priorities in AHP. European Journal of Operational Research 187, 1422-1428 (2008)

4. Feng, S.C., Joung, C.: Development Overview of Sustainable Manufacturing Metrics. In: Proceedings of the 17th CIRP International Conference on Life Cycle Engineering, pp. 6$12(2010)$

5. Global Reporting Initiative, Sustainability Reporting Guidelines, ver. 3.1 (2011), http: / /www.globalreporting.org/ (accessed June 2, 2011)

6. Kiritsis, D., Marco, G.: Report from workshop 2: Sustainable products and production, services and management. In: IMS 2020-Proceedings from IMS 2020 Summer School on Sustainable Manufacturing (2010)

7. Laurent, A., Olsen, S.I., Hauschild, M.Z.: Carbon footprint as environmental performance indicator for the manufacturing industry. CIRP Annals - Manufacturing Technology 59, 37-40 (2010)

8. Sustainable Manufacturing Indicators Repository, Engineering Laboratory, National Institute of Standards and Technology, http: //www.mel.nist.gov/msid/SMIR/ (accessed December 20, 2012)

9. Stark, J.: Product Lifecycle Management, pp. 1-16. Springer, London (2011)

10. Savino, M., Mazza, A., Ouzrout, Y.P.: Maturity Model: A Multi-Criteria Assessment in Southern Italy Companies. International Journal of Operations and Quantitative Management 18(3), 159-180 (2012)

11. Lee, S.G., Ma, Y.S., et al.: Product lifecycle management in aviation maintenance, repair and overhaul. Computers in Industry, 296-303 (2008)

12. Stark, J.: Product Lifecycle Management -21st Century Paradigm for Product Realisation. Springer, London (2005)

13. Sharma, A.: Collaborative Product Innovation: Integrating Elements of CPI via PLM Framework. Computer-Aided Design 37(13), 1425-1434 (2005)

14. Sharif, N.: Technology Strategy in Developing Countries: Evolving from Comparative to Competitive Advantage. International Journal of Technology Management 10(10), 1-33 (1997)

15. Trotta, M.: Product Lifecycle Management: Sustainability and knowledge management as keys in a complex system of product development. Journal of Industrial Engineering and Management 3(2), 309-322 (2010)

16. Vengugopalan, S.R., et al.: Application of AHP for PLM Tools Selection. Product Lifecycle Management: Fostering the culture of innovation. In: PLM-SP4, pp. 111-125 (2008)

17. Van Looy, A., De Backer, M., Poels, G.: Towards a Decision Tool for Choosing a Business Process Maturity Model. In: Peffers, K., Rothenberger, M., Kuechler, B. (eds.) DESRIST 2012. LNCS, vol. 7286, pp. 78-87. Springer, Heidelberg (2012) 